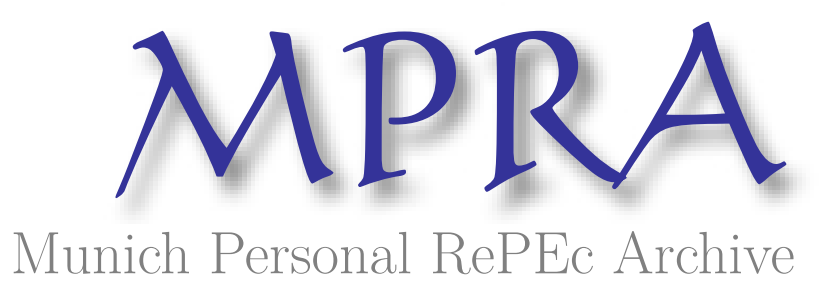

\title{
Investment timing and optimal capacity choice for small hydropower projects
}

Bøckman, Thor and Fleten, Stein-Erik and Juliussen, Erik and Langhammer, Håvard and Revdal, Ingemar

Norwegian University of Science and Technology (NTNU)

11 June 2006

Online at https://mpra.ub.uni-muenchen.de/2693/

MPRA Paper No. 2693, posted 11 Apr 2007 UTC 


\title{
INVESTMENT TIMING AND OPTIMAL CAPACITY CHOICE FOR SMALL HYDROPOWER PROJECTS
}

\author{
Thor Bøckman, Stein-Erik Fleten ${ }^{1}$, Erik Juliussen, Håvard J. Langhammer, Ingemar Revdal
}

Department of Industrial Economics and Technology Management, Norwegian University of Science and Technology, NO-7491 Trondheim, Norway

\begin{abstract}
This paper presents a method for assessing small hydropower projects that are subject to uncertain electricity prices. We present a real options-based method with continuous scaling, and we find that there is a unique price limit for initiating the project. If the current electricity price is below this limit it is never optimal to invest, but above this limit investment is made according to the function for optimal size. The connection between the real option and the physical properties of a small hydropower plant is dealt with using a spreadsheet model that performs a technical simulation of the production in a plant, based on all the important choices for such a plant. The main results of the spreadsheet are simulated production size and the investment costs, which are in turn used for finding the value of the real option and the price limit. The method is illustrated on three different Norwegian small hydropower projects.
\end{abstract}

\section{KEYWORDS}

OR in Energy, Real Options, Continuous Scaling, Project Evaluation, Hydropower

\section{INTRODUCTION}

Small hydropower is an important source of new renewable electricity generation capacity. If developed sensitively, it has few environmental risks, and increased use will contribute to curbing $\mathrm{CO} 2$ emissions thereby mitigating global warming. We expect an increased interest in small hydropower over the coming years, as it in many cases is the most economic method of renewable power generation. In addition, many countries have taken an interest in increased distributed generation, either as a good method in places of lacking infrastructure (islands or places with no power lines) or just as an addition to the existing power supply. Along with increasing energy prices worldwide, these developments will lead to a growing need for investment evaluation of small hydropower projects.

We use the definition of small hydropower as advocated by the European Small Hydropower Association of the European Commission, whereby small hydropower plants refers to capacities up to $10 \mathrm{MW}$. The capacity limit varies by country; in China it can be $25 \mathrm{MW}$, in India $15 \mathrm{MW}$, and in Sweden 1.5 MW.

There is significant untapped potential, especially in countries where there is also large scale hydro, e.g. China, Canada, Norway, Australia, New Zealand, and countries in South America,

\footnotetext{
${ }^{1}$ Corresponding author. Tel +47 91897707, e-mail stein-erik.fleten@iot.ntnu.no
} 
Africa and of the former Soviet Union. In the EU there was more than $11600 \mathrm{MW}$ small hydro installed in 2005, and the remaining economic potential is estimated to $26 \mathrm{TWh} /$ year by the European Small Hydropower Association (ESHA 2005). This includes the new EU Member states and Candidate countries, and the former EU-15. The remaining economic potential in Norway is estimated to $25 \mathrm{TWh} /$ year by the Norwegian Water Resources and Energy Directorate (NVE 2005). In the EU study the assumptions are not stated, but the Norwegian study includes all projects not in protected zones having an investment cost of less than $37.5 €$ cents/kWh annual generation.

The investor considering a potential project faces two investment problems; if or when to invest and the optimal capacity choice. This decision is very important because of its irreversibility. Once a plant has been constructed it has little alternative use, as the different components often are tailor-made. The investment will for all practical purposes be a sunk cost. Expanding the plant is also very expensive. This means that it is very important to make the correct investment decision; choosing the optimal investment time and the optimal plant size.

Uncertainty in the future power prices and variation in the water inflow over the year and from one year to another complicates this capacity choice. Small hydropower installations are usually "run of the river" plants, which means that there is no water storage. The water has to be lead through the hydro turbine right away or it will be lost. The capacity of the power plant will decide how much of the inflow to utilize. A larger plant can utilize more water; produce more energy in periods of great inflow, than a smaller plant. On the other hand a large plant has higher investment costs and will have lower efficiency in periods with less inflow. These factors give a probable capacity range for a hydropower plant, but finding the optimal capacity is difficult when both the inflow and the future power prices are uncertain. The scope of this paper is to develop a model for this investment decision.

With uncertainty and irreversibility, McDonald and Siegel (1986) and Dixit and Pindyck (1994) have shown that real options analysis leads to better investment decisions than traditional net present value analysis when the investor has the opportunity to postpone his investment. Their investment timing model must be expanded when the investor must are given additional choices in the design of the project, such as the production capacity. Dias, Rocha and Teixeira (2003) and Décamps, Mariotti and Villeneuve (2006) consider the choice between several capacities (projects) and show that the introduction of more choices may lead the investor to wait more - to see which of the capacity (project) choices will turn out to be optimal. Fleten, Maribu and Wangensteen (2005) build on those models to analyse the choice between known discrete capacities for small-scale renewable power plants. In the McDonald and Siegel (1986) model there is a triggering level of the project value or output price at which it is optimal to invest. If the design choices are discrete, the investment decision rule can not be expressed in terms of a unique trigger level, rather, there will be different designs (projects, capacities) for different intervals of the uncertain state variable. Dangl (1999) develops theory and methodology for investment and continuous capacity choice under uncertain demand. In this paper we use these ideas to develop a continuous model for investment and capacity choice for small hydropower plants in a power market with uncertain prices. One of the effects of having continuous design choices is that the investment rule is again a simple trigger strategy. If a project has a trigger price above the currently observed price state, one should wait, and if a project has a trigger price below the currently observed price, one should invest immediately choosing the capacity that gives the highest net present value. 
The remainder of the article is organized as follows. Section 2 briefly explains the engineering part of the model, Section 3 discusses modelling of uncertain electricity prices, Section 4 presents the real option model, Section 5 and 6 explains how the parameter values and investment costs are estimated, Section 7 contains case studies using the model and a brief discussion on the impact of price- and inflow seasonality, section 8 and 9 are discussion and conclusions.

\section{PHYSICAL PRINCIPLES OF HYDROPOWER PLANTS}

The physical principles of a hydropower plant are simple. The potential energy caused by gravity of water at an elevated level is transformed to water pressure (and some kinetic energy) as the water is lead through pipes from a water inlet down to a power station. In the power station this energy is first transformed to mechanical energy in a hydropower turbine and then to electricity in a generator. The amount of energy is decided by the flow of water and the elevation of the inlet. This principle is the basis for all kinds of hydropower stations.

When constructing a hydropower plant the goal is to transform the potential energy into electrical energy as efficiently as possible, to the lowest costs possible. Finding the optimal choice is not simple. For instance, pipes with a larger diameter will cause less energy loss on account of friction than smaller ones, but they are more expensive. A turbine with a high capacity is able to utilize more water when the inflow is high, but has lower efficiency when the inflow is lower, which is the case most of the time. The water inflow through the year and from one year to another is uncertain in addition to the uncertain electricity price. The investor in a small hydropower plant will have to make an optimal investment, choosing the timing and capacity of the plant, for a project with a probable lifetime of 30 years, taking these uncertainties into account.

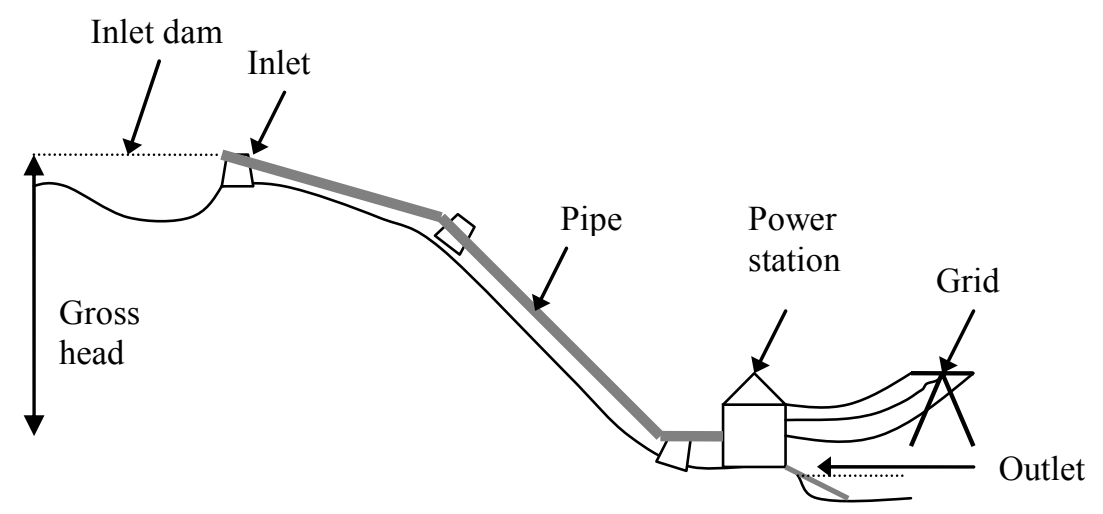

Figure 1: Illustration of a hydropower plant

\subsection{Simulation of Production and Cash Flows}

To support the optimal choice of capacity, it is necessary to model the physical properties of a small hydropower plant. To do this we find spreadsheet based software useful in combining 
simulation of the physics of a small hydropower plant with cash flow-based real options calculations. The spreadsheet model we have developed utilizes historical inflow with weekly measurement, normally for 30 - 60 years; additional input includes all key figures for the projects such as gross head, length of the inflow pipes, distance to an electrical power-grid and so forth. These are physical characteristics of the utmost importance for the development cost and production capacity of a hydropower project.

To calculate the total construction costs of different plants, we have made use of engineeringbased empirical cost functions for all important component choices and sizes. To calculate energy production for different plants we have made use of functions for the efficiency of all key components and processes, such as friction loss and turbine, generator and transformer efficiency. These functions are combined, forming a function for the total efficiency of the plant.

Based on these necessary inputs the spreadsheet calculates investment cost and the expected annual generation. These two figures are key in the real options part of the model. They are the basis of the functions for the investment cost and the value of the project.

\section{ELECTRICITY PRICE}

The electricity price, as mentioned earlier, is the most important uncertain factor when assessing a small hydropower project. In the literature it is common to differentiate between the short-term and the long-term development of the price, see e.g. Pilipovic (1997) and Schwartz and Smith (2000). The factors that influence the price in the short-term are for instance the weather, the short run availability of production capacity and transmission bottlenecks. The long-term factors include issues such as demand growth uncertainty, regulatory uncertainty, and fuel and substitute energy prices.

Lucia and Schwartz (2002) discuss several models for the electricity price. They present a two-factor model which deals with both the short-term and the long-term development of the electricity price. Here the short-term variations are represented by a mean-reverting OrnsteinUhlenbeck process and the long-term by an arithmetic Brownian motion. They find that this model works better than a one-factor mean-reverting process. Schwartz and Smith (2000) use a similar model for commodities, and they argue that the in the long-term only their geometric Brownian motion matters. Pindyck (2001) discusses the long term evolution of commodity prices, and claims that for long-term energy-related investments a geometric Brownian motion will lead to small errors.

When assessing a long-term investment project (such as a run-of-the-river hydropower plant), the expected value coming from the mean-reversion component is zero, and it will suffice to concentrate on the long-term price. This is shown in Schwartz (1998).

\subsection{Long-Term Price}

When deciding on a long-term power generation project the current spot price is not really interesting, as it can be heavily influenced by short-term factors. What is relevant is the uncertainty in the time-average price over the lifetime of the hydropower project. As indicator 
for this long-term price, Schwartz (1998) introduced the shadow spot price, which is a price reflecting long-term equilibrium, or equivalently it is a spot price that is "corrected" for short term factors currently away from their mean.

The shadow spot price today can be inferred from currently observed prices of long-term forward contracts; Section 5.4 will demonstrate how this can be done. Since forward contracts on electricity are certainty-equivalent prices, the dynamics estimated for the shadow spot price is adjusted for electricity price risk. This implies that the correct cost of capital for discounting is the risk-free interest rate $r$.

\section{THE MODEL}

\subsection{Production Costs}

In a small hydropower plant the operation and maintenance costs are divided into two parts. First there is a fixed cost that is independent of the production size. This mainly consists of maintenance of plant and waterways but also supervision and control of the plant. Next there is a cost that varies with the size of the production; this cost consists of charges for using the power grid and costs in connection with sales. The grid cost in turn consists of a general cost for using the grid and a charge that depends on the grid-situation at the point of the power plant. This charge can also be a source of income for the plant, if for instance there is a need for reactive power in the grid. The last part of the variable cost is in connection with sales. A small hydropower plant usually sells power to or through larger electricity supplying companies and must pay a fee for this service.

We separate these two operation costs. The fixed cost is taken into account as a part of the investment cost. The reason for this is that once a small hydropower plant has been constructed it is almost never optimal to shut it down, this means that the fixed production costs will almost certainly occur. We have tried different models for dealing with the variable cost. The goal has been finding a simple solution, and at the same time including these costs properly. We choose to assume a geometric Brownian motion for the contribution margin. The available data indicates that the variable cost is fixed per produced $\mathrm{MWh}$ and we therefore define the contribution margin, $\theta$

$\theta=P-c$

where $P$ is the (shadow) price of electricity and $c$ is the production cost per unit. We assume that $P$ is always greater than $c$, which implies that $\theta$ always is nonnegative. This assumption is supported by the values found in this article where $c$ is less than $4 \%$ of typical values of $P$. Furthermore, hydropower is the technology with the lowest marginal cost, close to zero. We would expect that electricity market prices, especially long term prices, never will go below the lowest marginal cost for all producers.

The variable $\theta$ follows a geometric Brownian motion:

$d \theta=\alpha \theta d t+\sigma \theta d z$ 


\subsection{The value of the plant and the investment cost}

To find an optimal investment strategy in hydropower plants we need an expression for the value of a small hydropower plant once constructed, and an expression for the investment cost $I(m)$, where $m$ is project size in $\mathrm{MWh}$ /year. First we describe the value function $V(m, \theta)$, that is the value of the project with assets in place, as a function of the project's size and the contribution margin. Next we describe the investment cost $I$ as a function of the project size $m$.

In general the value of a project is the value of its output less the production costs, and this also holds for small hydropower plants. The value of the plant is the size of the average production during the lifetime of the plant multiplied by the contribution margin discounted over the lifetime by the correct discount rate:

$V(m, \theta)=\theta m \varepsilon$

where

$\varepsilon=\frac{1}{\delta}\left(1-e^{-\delta T}\right)$

$\delta=r-\alpha$

here $\delta$ is the growth-adjusted cost of capital. It is usually denoted a convenience yield, which in the case of storable commodities represents the benefits of holding the commodity in storage rather than holding a futures contract on the commodity. For non-storable commodities such as electricity, it must be interpreted as the relative benefit of delivering the commodity earlier rather than later $^{2}$. The $\delta$ is the correct discounting factor when the electricity price is on average expected to grow by $\alpha$ and the discount interest rate is $r ; \varepsilon$ is the expression for discounting a fixed cash flow by $\delta$ over $T$ years.

We have assessed the connection between the investment cost and the capacity choice for different small hydropower projects. Our findings support our opinion that each hydropower project has a finite maximum capacity, and as the chosen capacity approaches this limit, each new unit of capacity becomes extremely expensive. An exponential relationship between investment cost and capacity is consistent with our data and with the model of Dangl (1999). The marginal investment cost rises with the size of the project, in other words each extra unit of capacity is more expensive than the last one. The general expression for investment costs $I(m)$ is:

$I(m)=A e^{b m}$

here $A$ and $b$ are constants, and $m$ is the energy production of the hydropower plant in an average year.

\footnotetext{
${ }^{2}$ As the convenience yield can be determined by the slope of the forward curve, the above interpretation of convenience yield is due to the fact that a discounted forward price is the current value of future physical exchange of the commodity. If the forward curve is sufficiently upward sloping, there is a relative benefit to delivering the commodity later rather than earlier.
} 
A small hydropower project is a price-taker. Once you have fixed the production capacity for a small run-of-the-river hydropower plant, it is always optimal to produce the capacity as long as the price is higher than the variable production cost, which is the case for all practical purposes. The average production per year is a function of the capacity choice, but the inflow to the plant and thereby the production varies from year to year. The optimal investment size is found by maximizing net present value with respect to $m$, and this occurs when the marginal value of an extra unit of production capacity equals its marginal cost.

$$
\max V(m, \theta)-I(m) \Rightarrow \frac{\partial}{\partial m} V(m, \theta)=\frac{\partial}{\partial m} I(m)
$$

We solve this expression for the average energy capacity $m$.

$$
m^{*}=\frac{\ln \frac{\theta \varepsilon}{A b}}{b}
$$

This expression gives the energy production choice as a function of the contribution margin, which in turn vary directly with electricity price. The connection between energy production and capacity choice is found through simulation.

\subsection{The Value of the Real Option}

The next step is valuing the real option $F$; the option to invest, which also takes into account the possibility to postpone the investment decision. The option to invest is found using Dixit and Pindyck's (1994) approach, assuming that an investor has a monopoly right to invest, doing so at a time chosen freely. The only stochastic factor affecting the value of the investment is the long-term electricity price. The underlying variable for the option, the contribution margin, is governed by the already mentioned Geometric Brownian motion:

$d \theta=\alpha \theta d t+\sigma \theta d z$

Over a short period of time, $d t$, the total return from holding the investment opportunity $F$ is simply its expected change in value. With a rate of return $r$ this is (Dixit and Pindyck (1994)):

$r F d t=E(d F)$

Expanding $d F$ using Ito's Lemma we get the quadratic differential equation:

$$
\frac{1}{2} \sigma^{2} \theta^{2} F^{\prime \prime}(\theta)+\alpha \theta F^{\prime}(\theta)-r F=0
$$

the particular solution to this problem is:

$$
F(\theta)=D_{1} \theta^{\beta_{1}}
$$


where $D_{1}$ is a constant to be determined. The constant $\beta_{1}$ is a known function of $r, \delta$ and $\sigma$, and is found by putting (12) into (11) and selecting the positive root of the resulting quadratic equation ${ }^{3}$.

\subsection{The Optimal Investment Strategy}

The decision to exercise is a matter of balancing the following:

- Investing later saves interest on the investment cost, $I(m)$.

- Investing now means that the investor starts to receive the cash flows of the project.

- Investing now means losing the opportunity to avoid losses if prices should go very low.

The optimal investment strategy follows from two conditions that are consistent with the above tradeoff. The first is the "value-matching" condition, which says that when one invests, the value of the investment opportunity equals the net present value of the project. We use $F(\theta)$ for the value of the real option as a function of contribution margin $\theta$ :

$F\left(\theta^{*}\right)=V\left(\theta^{*}, m^{*}\left(\theta^{*}\right)\right)-I\left(m^{*}\left(\theta^{*}\right)\right)$

Substituting in (6), (8) and (12) gives the value of the real option as a function of the state variable and the trigger $\theta^{*}$

$F\left(\theta ; \theta^{*}\right)=D_{1}\left(\theta^{*}\right) \theta^{\beta_{1}}=\frac{\left(\theta^{*}\right)^{1-\beta_{1}} \varepsilon}{b}\left(\ln \frac{\left(\theta^{*}\right) \varepsilon}{A b}-1\right) \theta^{\beta_{1}}$

The second condition entails choosing the investment trigger level such that the value of the investment opportunity is as large as possible. The trigger level to choose is found by maximizing $F\left(\theta ; \theta^{*}\right)$ with respect to $\theta^{*}$, giving ${ }^{4}$

$\theta^{*}=\frac{A b}{\varepsilon} e^{\left(\frac{\beta_{1}}{\beta_{1}-1}\right)}$

Equation (15) is then inserted into equation (14) to obtain:

$D_{1}=\frac{\left(\frac{\varepsilon}{A b}\right)^{\beta_{1}} e^{-\beta_{1}} A}{\beta_{1}-1}$

The trigger $\theta^{*}$ is the unique trigger level for investing in the project. When the net earnings is below this limit:

$\theta<\theta^{*}$

\footnotetext{
${ }^{3}$ Selecting the negative root, $\beta_{2}$, would mean that the option value decreases with increasing contribution margin.

${ }^{4}$ This can be done by setting the derivative of $F\left(\theta ; \theta^{*}\right)$ with respect to $\theta^{*}$ to zero and solving for $\theta^{*}$.
} 
it is never optimal to invest in the project, no matter how you vary the parameters of the plant. Recall that $P$ is the long-term/shadow price of electricity; this means that if you evaluate a project using this method and find that the long-term price is higher than the net earnings plus the production cost

$P>\theta^{*}+c$

it is optimal to invest immediately. The capacity choice of the project is decided according to the function for optimal energy production as a function of price:

$m^{*}=\frac{\ln \frac{\theta \varepsilon}{A b}}{b}$

The value of a small hydropower project is accordingly:

$P>P^{*}: V\left(m^{*}, P\right)-I\left(m^{*}\right)$

$P \leq P^{*}: F(P)$

When the shadow price is above the price trigger $P^{*}=\theta+c$, the project should be initiated immediately and its value is the net present value. When the shadow price is below the price trigger, the value is equal to $F$, the value of the real option.

\section{DETERMINING MODEL PARAMETERS}

In this section we will present the parameters we have estimated or found for assessing different small hydropower projects.

\subsection{Required Rate of Return}

We have covered the price risk when dealing with certainty-equivalent forward prices, and assumed that there are no other risk factors involved. In reality there are some candidate risk factors that may influence the required rate of return. These include technical and political risk. The technical risk entails the risk that components will malfunction and will have to be replaced, but also the risk that the plant has not been planned and constructed properly. Further there is a risk of bankruptcy problems if for instance there are unusually many years in a row with a low inflow. The political risk entails the risk that the government changes the taxes for small hydropower plants or starts subsidising this type of electricity production. In our opinion the potential upside is larger than the downside for the political risk. The 
technical and political risks are considered to be minor. The risk free rate will therefore be the appropriate discount factor. For simplicity the risk free rate is set to $5.8 \%$.

\subsection{Effective Life}

The effective life of a small hydropower projects is difficult to estimate, it varies from project to project. It is also difficult to decide what is normal maintenance, and what is reinvestment in the project. Normally though the effective life will be at least 25 years. For larger hydropower plants the effective life can be more than 50 years. To simplify the calculations we assume that the effective life of the projects is 30 years and that the payment period for the debt financing is the same.

\subsection{Cost of Generation}

The variable production cost consists of tariffs for grid use and costs in connection with sales. We have estimated these costs from an actual offer from a Norwegian electricity company and official costs in connection with grid-use in Norway. The cost for delivering electricity into the grid is $0.63 € / \mathrm{MWh}$, this is a guiding fee for 2005 decided by the Norwegian authorities. In addition there is a grid tariff that depends on the local power flows. The grid situation dependent tariff can be both positive and negative, it is normally between $+10 \%$ and $-10 \%$ of the electricity price. This fee is a cost for most plants. We have used a cost of 0.25 $€ / \mathrm{MWh}$. The electricity is normally sold through an electricity company that takes part in the Nordic power exchange, Nord Pool, and the cost for selling the electricity therefore depends on what the pool-participating electricity companies offer. This is estimated to $0.31 € / \mathrm{MWh}$. To sum up our estimated variable production cost is:

Total variable production cost $=$ delivery $\cos t+$ grid-fee + sales $\operatorname{cost}=1.19 € / \mathrm{MWh}$

\subsection{Annual Growth of the Contribution Margin}

The best way of estimating the growth of the long-term, risk adjusted electricity price is from a large selection of traded long-term contracts. Unfortunately these contracts are mostly done bilaterally and accordingly it is difficult to get information about them. Another option is price-forecasting models. However, when developing such a model, one will have to make a number of assumptions and simplifications that are all a potential source of error. In our opinion this will generally be a greater source of error than that of having a limited selection of market data. Assuming that the forward market is fairly efficient, traded contracts contain a lot of information. Therefore we choose to use the best available information on traded and estimated long-term contracts.

We have estimated the annual growth rate of the shadow spot price from five one-year forward contracts for five consecutive years, 2007-2011, in the Nordic electricity market. The two first contracts were traded on April $14^{\text {th }} 2005$ and the three others were estimated on the same date by a query in the over-the-counter market. Table 1 contains the prices and the resulting values for contribution margin: 
Table 1: Prices and resulting values for contribution margin

\begin{tabular}{llll} 
Year & $\begin{array}{l}\text { Price of one- } \\
\text { year forward } \\
\text { [€/MWh] }\end{array}$ & $\begin{array}{l}\text { Variable } \\
\text { production } \\
\text { [€/MWH] }\end{array}$ & $\begin{array}{l}\text { Contribution } \\
\text { margin } \\
\text { [€/MWh] }\end{array}$ \\
\hline 2007 & 33.25 & 1.19 & 32.06 \\
2008 & 33.38 & 1.19 & 32.19 \\
2009 & 33.63 & 1.19 & 32.44 \\
2010 & 33.88 & 1.19 & 32.69 \\
2011 & 34.13 & 1.19 & 32.94
\end{tabular}

According to the geometric Brownian motion the expected contribution margin evolve as:

$E(\theta(t))=\theta_{0} e^{\alpha t}$

Here $\alpha$ is the annual growth of contribution margin. This has been estimated to $0.69 \%$, using exponential regression on the data in Table 1. The corresponding fixed value of contribution margin, $\theta_{0}$, for 2005 was $31.6 € / \mathrm{MWh}$. This is used as an estimate of the present long-term electricity price.

\subsection{Annual Volatility of the Contribution Margin}

The annual volatility has been estimated from the prices of one-year forward contracts traded three years in advance at the Nordic electricity exchange Nord Pool. We have used prices for the years 2001-2004, meaning the prices are for forward contracts on the years 2004-2007. We have subtracted the variable production cost in the same fashion as before and found the corresponding values for contribution margin. The annual volatility has been calculated with the formula

$$
\sigma=\sqrt{\frac{1}{n-1} \sum_{i=1}^{n}\left(\frac{\ln \theta_{i}-\ln \theta_{i-1}}{\sqrt{t_{i}-t_{i-1}}}-\frac{1}{n} \sum_{i=1}^{n} \frac{\ln \theta_{i}-\ln \theta_{i-1}}{\sqrt{t_{i}-t_{i-1}}}\right)^{2}}
$$

which is valid for lognormal distributions, a prerequisite for geometric Brownian motion. The resulting annual volatility was $\sigma=13.35 \%$. 


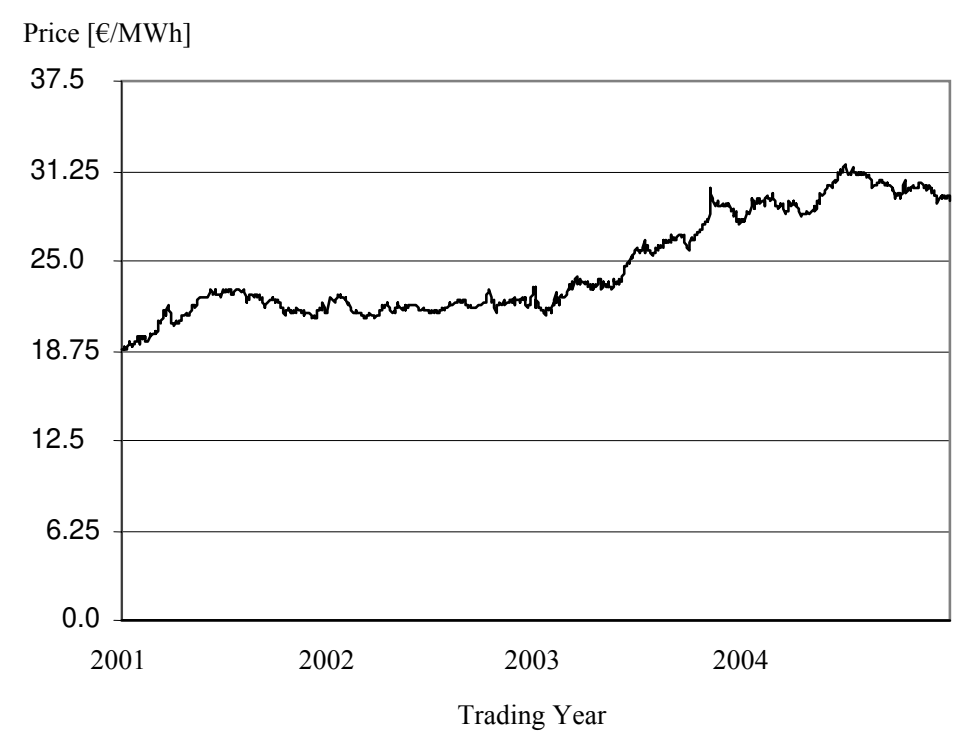

Figure 2: Prices of one-year forwards traded three years in advance

Figure 2 shows some of the data used for estimating the volatility. It shows a time series of forward prices for contracts with a delivery period of one year and maturity three years ahead. The data is for four years of 248 trading days each.

\section{INVESTMENT COST}

Investment costs in small hydropower projects depend on a large number of technical choices. Accordingly it is difficult to estimate a function for the investment cost which is only dependent on one variable, the average production size $m$. Some of the most important variables for the production capacity of a plant are the choice of turbine, the size of the pipes and the maximum operating flow. In order to establish an unambiguous function for the investment cost we first decide the turbine type. Next the operating flow and pipe diameter are varied, while all other variables are left unchanged or vary with these changes. The reason for choosing the operating flow and the pipe diameter is that they to a great extent decide the production capacity of a small hydropower plant.

The investment cost function is found in the aforementioned spreadsheet. To fix the relation between the two variables we make the assumption that the maximum water speed in the pipes should be $3 \mathrm{~m} / \mathrm{s}$. The ideal speed is normally between 2 and $4 \mathrm{~m} / \mathrm{s}$ and on average we achieve the best results with this number. As we have to make some simplifications to establish a connection between average production size and investment cost, this will in our opinion not lead to great errors for this type of analysis. The spreadsheet model estimates the investment cost from an array of possible capacity choices where each has a maximum water speed of $3 \mathrm{~m} / \mathrm{s}$. The array also contains the investment cost, $I$, and average production, $m$, for each choice. The investment cost function is estimated using regression for the investment costs and average productions in the array. 


\section{CASE STUDIES}

In this section we will present the results of using our real options approach on three different Norwegian small hydropower projects.

The exogenous variables that we have discussed already are summed up in Table 2 .

Table 2 : Exogenous variables used in the examples

\begin{tabular}{llll} 
Constant & Symbol & Value & \\
\hline Risk-free rate & $r$ & $5.80 \%$ & \\
Effective life & $T$ & 30 & years \\
Annuity factor & $\varepsilon$ & 15.3 & \\
Variable production cost & $c$ & 1.19 & $€ / \mathrm{MWh}$ \\
Current long-term price & $P_{0}$ & 32.8 & $€ / \mathrm{MWh}$ \\
Annual growth of $\theta$ & $\alpha$ & $0.69 \%$ & \\
Annual volatility of $\theta$ & $\sigma$ & $13.35 \%$ &
\end{tabular}

These will be the same for all the projects.

\subsection{Project 1}

The first project is a Norwegian small hydropower plant named Rivedal in Sogn og Fjordane county, Norway. This plant was completed February 2005. We have data for weekly inflow for seventy-four years. The project has a $200 \mathrm{~m}$ drop, the average inflow is $1.21 \mathrm{~m}^{3} / \mathrm{s}$. For this plant we have chosen a maximum operating flow of $3.07 \mathrm{~m}^{3} / \mathrm{s}$, the diameter of the pipes is $1.14 \mathrm{~m}$ and we have chosen a Pelton turbine. Table 3 presents the results for plant 1 .

Table 3: Results for project 1

\begin{tabular}{lll} 
Symbol & Value & \\
\hline$A$ & $4.72 \cdot 10^{5}$ & \\
$b$ & $1.37 \cdot 10^{-4}$ & \\
$D_{1}$ & 425 & \\
$\theta^{*}$ & 20.9 & $€ / \mathrm{MWh}$ \\
$P^{*}$ & 22.1 & $€ / \mathrm{MWh}$ \\
$m^{*}\left(P^{*}\right)$ & 11675 & $\mathrm{MWh}$ \\
$m^{*}\left(P_{0}\right)$ & 14703 & $\mathrm{MWh}$ \\
$V(m, \theta)-I(m)$ & 3.6 & million $€$
\end{tabular}

The price trigger for constructing the power plant is $22.1 € / \mathrm{MWh}$. We have found the current long-term price to be $32.8 € / \mathrm{MWh}$. This means that this project should be initiated right away, with an average production size of $14703 \mathrm{MWh}$ per year, or 4.5 MW. The total value of the project is 3.6 million $€$. Figure 3 illustrates the sizes and values of this case. 


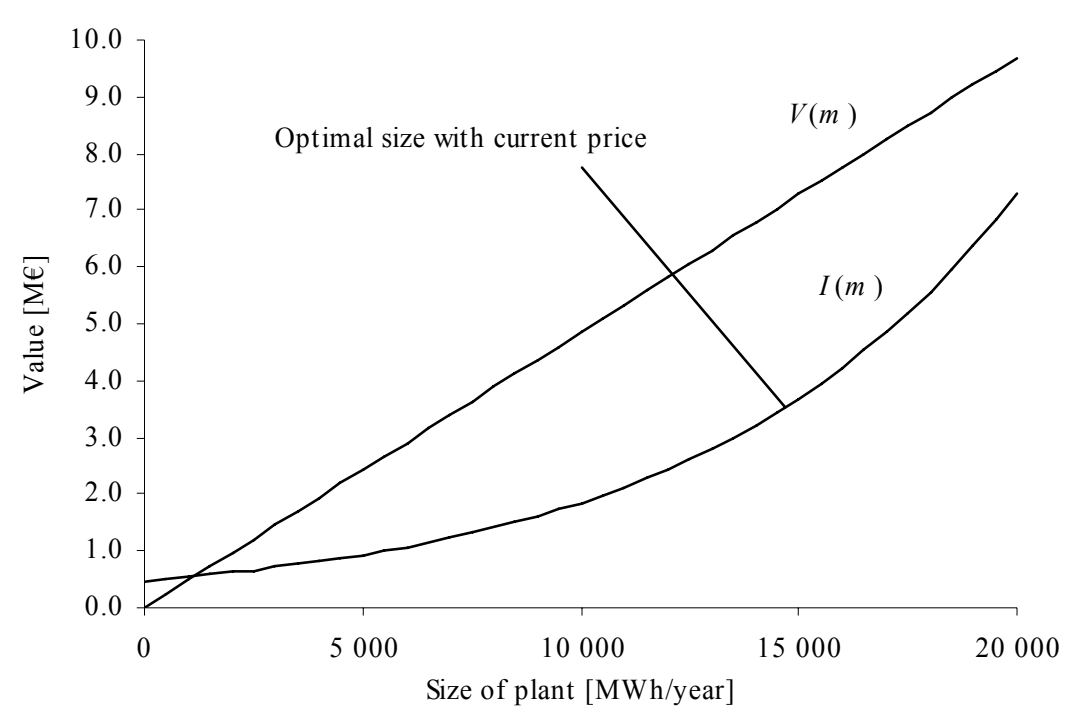

Figure 3: Value and investment costs for project 1 at the current price

It is also interesting to vary some of the constants to see how they affect the project. If we increase the volatility from $13.35 \%$ to $20 \%$ the trigger price is $P^{*}=30.6 € / \mathrm{MWh}$ which is still below the current long-term price, which means the project would still be worthwhile. If we raise the growth in the electricity market the price to $1 \%$, the trigger rises to $22.8 € / \mathrm{MWh}$ and the project is highly worthwhile. Extending the effective life of the plant from 30 to 40 years the price trigger falls to $20.0 € / \mathrm{MWh}$.

\subsection{Project 2}

For the second project we have data for weekly inflow for thirty-seven years. The project has a $150 \mathrm{~m}$ drop, the average inflow is $0.87 \mathrm{~m}^{3} / \mathrm{s}$. For this plant we have chosen a maximum operating flow of $1.95 \mathrm{~m}^{3} / \mathrm{s}$, the diameter of the pipes is $0.91 \mathrm{~m}$ and we have chosen a Pelton turbine. Table 4 presents the results for plant 1 .

Table 4: Results for project 2

\begin{tabular}{lll} 
Variables & Value & \\
\hline$A$ & $3.46 \cdot 10^{5}$ & \\
$b$ & $2.21 \cdot 10^{-4}$ & \\
$D_{1}$ & 199 & \\
$\theta^{*}$ & 24.7 & $€ / \mathrm{MWh}$ \\
$P^{*}$ & 25.9 & $€ / \mathrm{MWh}$ \\
$m^{*}\left(\theta^{*}\right)$ & 7239 & $\mathrm{MWh}$ \\
$m^{*}\left(\theta_{0}\right)$ & 8358 & $\mathrm{MWh}$ \\
$V(m, \theta)-I(m)$ & 1.9 & million $€$
\end{tabular}

This project is very good, as is project 1 . Figure 4 illustrates the net present value, and option value, as the contribution margin varies. Net present value is a nonlinear function of the contribution margin $\theta$, while investment cost turns out to be a linear function of $\theta$, the present value $V(m(\theta), \theta)$ is nonlinear in $\theta$. 


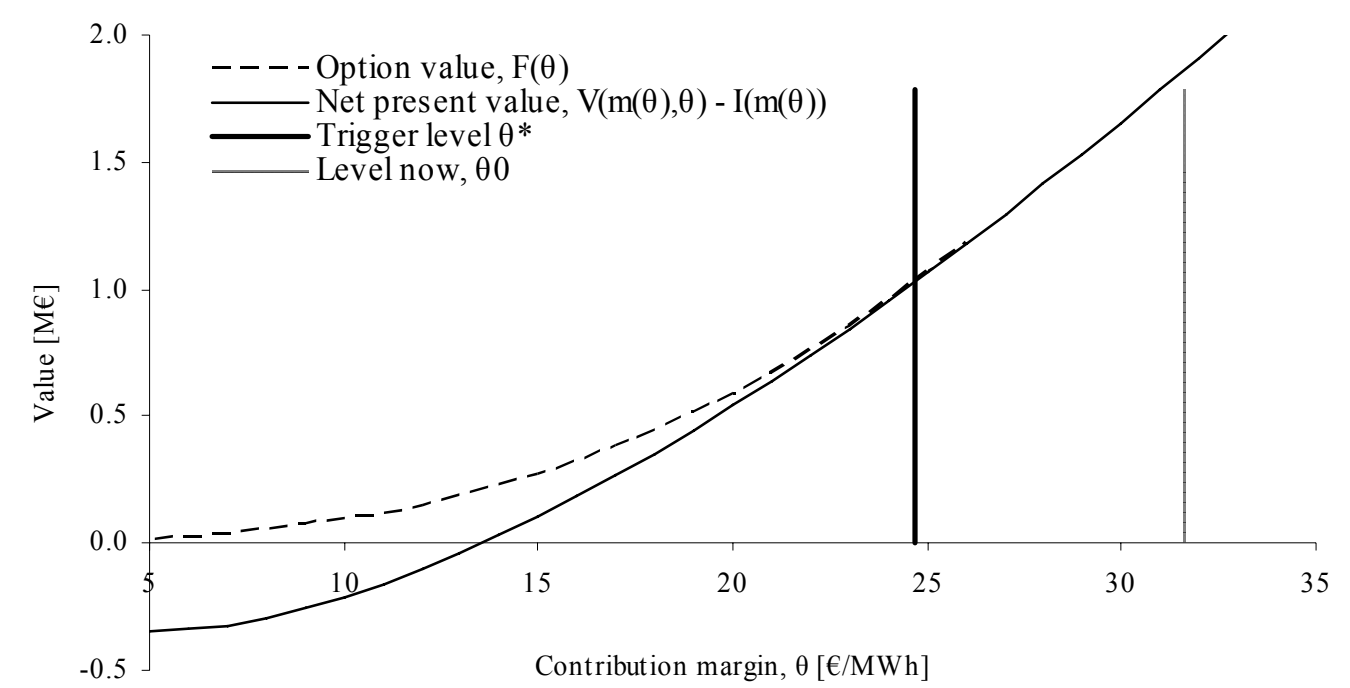

Figure 4: Net present value and real option value for project 2 at varying levels of the long-term electricity contribution margin

\subsection{Project 3}

With a drop of 102 meters and an average inflow of only $0.78 \mathrm{~m}^{3} / \mathrm{s}$, the third project is the smallest of the three. For this plant we have chosen a maximum operating flow of $2.40 \mathrm{~m}^{3} / \mathrm{s}$, and the diameter of the pipes is $1.01 \mathrm{~m}$. Table 5 presents the results for plant 3 .

Table 5: Results for project 3

\begin{tabular}{lll} 
Variables & Value & \\
\hline$A$ & $3.18 \cdot 10^{5}$ & \\
$b$ & $3.18 \cdot 10^{-4}$ & \\
$D_{1}$ & 87 & \\
$\theta^{*}$ & 32.6 & $€ / \mathrm{MWh}$ \\
$P^{*}$ & 33.8 & $€ / \mathrm{MWh}$ \\
$m^{*}\left(\theta^{*}\right)$ & 5029 & $\mathrm{MWh}$ \\
$m^{*}\left(\theta_{0}\right)$ & 4930 & $\mathrm{MWh}$ \\
$F\left(\theta_{0}\right)$ & 0.87 & million $€$
\end{tabular}

As one can see from the results, it is not optimal to build this power plant right away as the current long-term price is just below the optimal investment threshold of $33.8 € / \mathrm{MWh}$. If this threshold is reached one should build a plant with a production of $5029 \mathrm{MWh} / \mathrm{year}$. The value of the option is 4.1 million $€$. As is shown in Figure 5, using the standard net present value method based on discounted cash flows indicates an optimal production of $4930 \mathrm{MWh} /$ year with a total value of 0.87 million $€$, just below the option value. Should the contribution margin move upward toward the trigger, the slope of the present value curve $V(m)$ increases, causing an increase in the optimal capacity. 


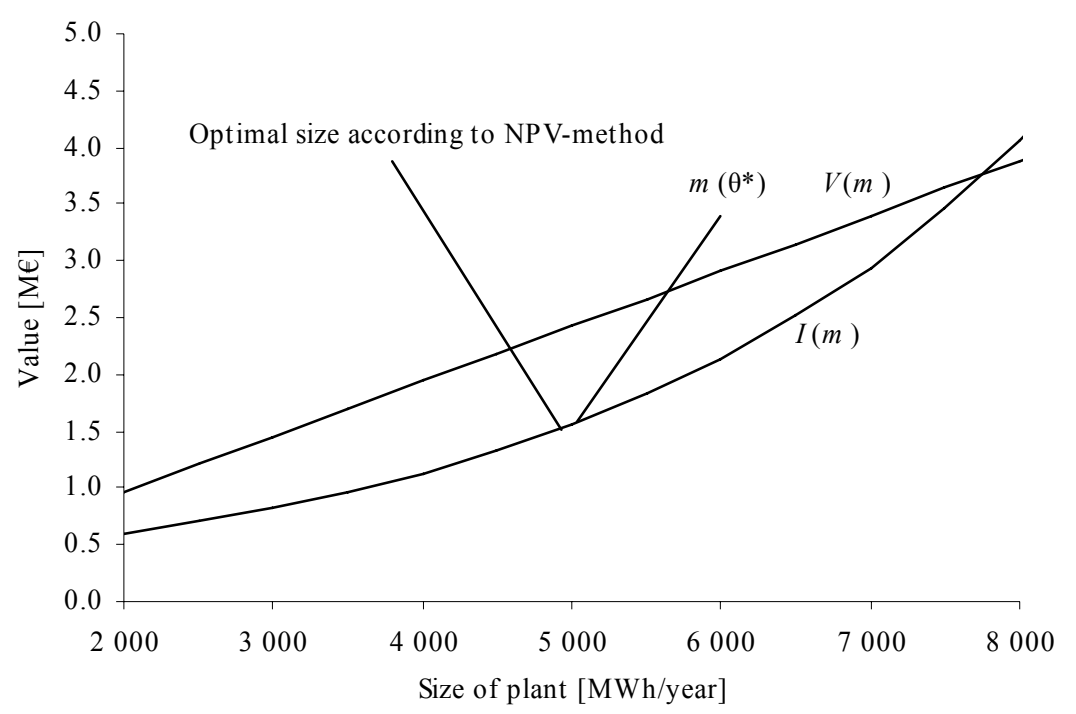

Figure 5: Value and investment cost for project 3, for varying plant capacities, at the current price. There is a very small difference between the optimal capacity if investment must be done now, versus if it can be postponed.

As the figure shows, according to the net present value method this project has a positive value and should be initiated if the project can not be postponed. However, the price of the real option is higher than the net present value, indicating that it is optimal to wait and observe the development of the electricity price. Investing now would give a net loss as you would gain the net present value but lose the real option value is which the larger of the two. When varying the growth we find a limit at $0.30 \%$ growth for investment in the project, for the volatility this limit is $12.7 \%$. So this project should be initiated soon if the current situation in the electricity market remains.

\subsection{Price - and Inflow Seasonality}

The Nordic power system has a share of hydropower of around $50 \%$. Due to this, prices are influenced by seasonal variations in water inflow.

There is a negative covariation between the electricity price and the water inflow during a year. Evidence of this is strongest during the spring flood. At this point in time, the prices usually are at their lowest value, while water inflow and production reaches their maximum level.

Geographical location also affects prices. Norway is divided into several price zones, and the zonal prices are determined by the local supply-demand conditions. Sometimes these prices are approximately equal, but when a bottleneck arises there might be significant divergence between the different zones.

The estimated long term electricity price, based on traded yearly forward contracts, does not capture these two aspects. This may lead to suboptimal values for optimal capacity and price limit. Specifically, when the capacity of the waterway, turbines and generators at a particular site are increased from a relatively high level, the much of the resulting extra annual generation capacity comes from increased generation during spring floods, at average prices 
that are lower than annual average prices. Multiplying annual average price with annual average generation will overestimate the annual revenue in such a case.

This gives rise to introducing a price correction factor, given by

$\rho \cdot S_{y}=\sum_{t} S_{r, t} \cdot\left(\frac{Q_{t}}{m}\right)$

where $\rho=\rho(m)$ is the correction factor, $S_{y}$ is the yearly average price of electricity, $S_{r, t}$ is the zonal price at hour $t, Q_{t}$ is the generation in hour $t$, and $m$ is the average annual generation.

An estimate of the price correction function, $\rho(m)$, can be obtained by regressing values of $\rho$ against their corresponding capacity values. The best fit of the data is achieved by a second order polynomial function, such that

$\rho(m)=D m^{2}+E m+F$

For this to be implemented in the real option model, the investment function must also be a second order polynomial function. Although this is a less realistic description of the investment costs, and leads to a slightly reduced fit of the data, it is still satisfactory. It is endeavoured to achieve an overall high $\mathrm{R}^{2}$ but at the same time an optimal fit in the relevant region of capacities.

The real option approach with the adjustments mentioned above is used to assess project 1 and project $2^{5}$. Project 1 originally has an optimal capacity of $14717 \mathrm{MWh} /$ year. When taking the price correction function into account this value drops to $12204 \mathrm{MWh} /$ year. For project 2 these values are 7915 and $6959 \mathrm{MWh} /$ year, respectively. The price triggers for project 1 and project 2 increases from 22.24 to $25.31 € / \mathrm{MWh}$ and from 23.80 to $23.86 € / \mathrm{MWh}$, respectively.

The results indicate that the optimal capacity decreases and the price trigger increases when price- and inflow seasonality are taken into consideration.

\subsection{Sensitivity}

The growth of contribution margin, $\alpha$, and the volatility of contribution margin, $\sigma$ are the most interesting factors for sensitivity analysis, because they decide the development of electricity price in the model. The price is the most important profitability factor for investment in small hydropower projects.

Increased growth leads to a higher price trigger and a higher value of the real option. The price-trigger rises because as the growth rises, also the expected return of the project rises, which makes it relatively cheaper to postpone the investment instead of getting the cash flows that the project would produce at the current price.

\footnotetext{
${ }^{5}$ The results from the simulation without $\rho(m)$ are slightly different from those in table 3 and 4 , because a slightly updated version of the spreadsheet model has been applied.
} 
Increased volatility leads to a higher price trigger and a higher value of the real option. The price trigger rises because the investor needs a higher price in order to invest in a more volatile market, where the chances of loss are greater. But as the volatility grows the possibility of profit also does. This means that the investment opportunity becomes more valuable. Higher volatility will lead to more valuable projects, but less investment activity. The main points are summarized in Table $6, \uparrow$ indicates an increased value.

Table 6: Summary of the most important sensitivity results, where $\uparrow$ indicates an increased value

$\begin{array}{ll}\alpha \uparrow & \theta^{* \uparrow} \\ \alpha \uparrow & F\left(\theta^{*}\right) \uparrow \\ \sigma \uparrow & \theta^{*} \uparrow \\ \sigma \uparrow & F\left(\theta^{*}\right) \uparrow\end{array}$

In Figure 6 we compare the growth rate sensitivity of the trigger level for the contribution margin, with and without the possibility of choosing the capacity freely. We use the data from project 1 , and for the case where capacity is fixed, $m=11675 \mathrm{MWh} / \mathrm{y}$. Regarding the formula for the investment trigger, the reader is referred to Dixit and Pindyck (1994).

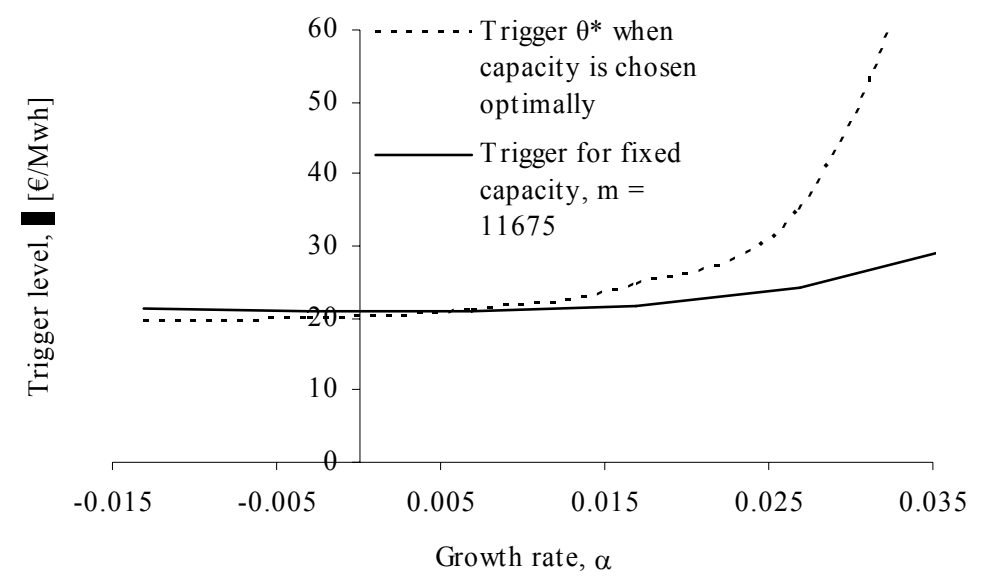

Figure 6: Optimal trigger level as a function of the risk-adjusted long-term growth rate of the contribution margin. Also shown is the case when capacity is fixed at the base case optimal value for project 1.

The notable higher sensitivity in the optimal trigger level when capacity level is chosen is due to the fact that when the growth rate increases, it becomes more attractive to invest in the future, but in the future prices will be higher so it pays to have a larger capacity and a higher trigger level. This interaction between the capacity choice and the trigger level is not present in the fixed capacity case.

A similar effect is seen in Figure 7, where the optimal trigger level $\theta *$ is shown for varying levels of volatility $\sigma$. Increased uncertainty increases the net present value of the project when the capacity can be chosen, because the optimal capacity increases when the trigger level increases. There is an extra value of waiting due to the uncertainty in determining the optimal capacity. 


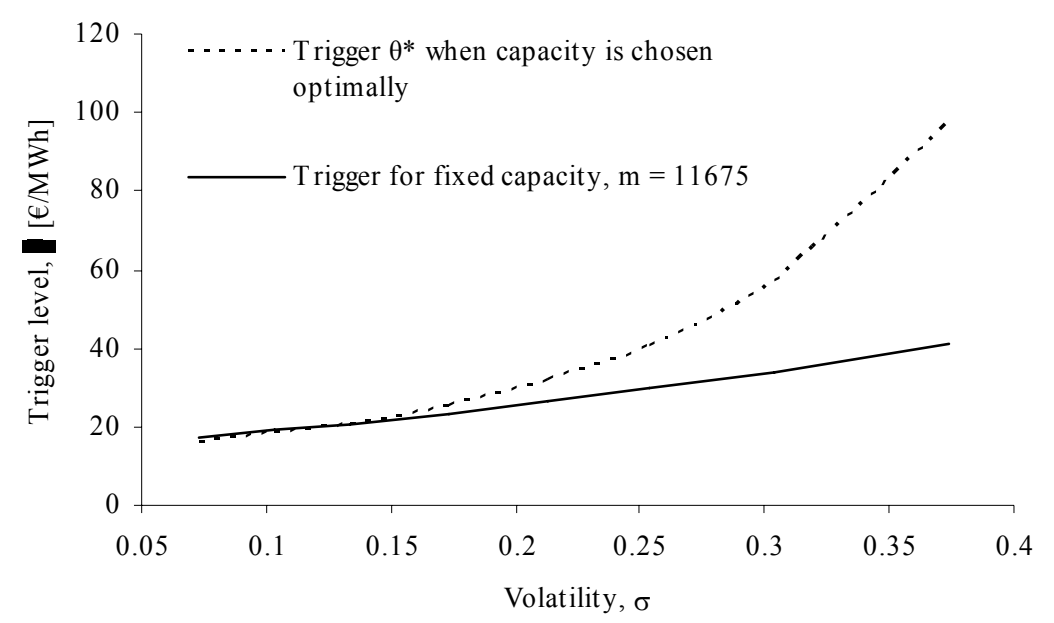

Figure 7: Optimal trigger level as a function of the long-term level of uncertainty in the contribution margin. Also shown is the case when capacity is fixed at the base case optimal value for project 1.

\section{DISCUSSION}

We have developed a real options model for small hydropower projects. This method entails finding functions for the value of the project and the investment cost. These functions in turn are combined with a real options method to find the unique trigger price for investing in the project, and a function for optimal size once it is optimal. The price risk one faces when building power plants is explicitly taken into account. There are however some important points we need to accentuate.

One weakness in our approach is the simplifications we have made to find an expression for the investment cost. We have chosen a water speed in the pipes, thereby fixing the relation between the maximum operating flow and the pipe diameter. If there were fewer design variables when constructing small hydropower plants, such simplifications would not be necessary. Other approaches for finding the investment cost function or optimization approaches for finding the best water speed would be very interesting expansions of our method.

The growth rate of the price has been estimated from five consecutive one year forward contracts and the volatility from four years of data for one-year forward contracts traded three years in advance. Ideally it would have been better having a larger data set, at least for estimating the growth, but the alternative of using price forecasting models will often lead to larger estimation biases. The volatility however is fairly stable for forward contracts more than one year into the future (Koekebakker and Ollmar (2005)), so in our opinion our estimate of the volatility ought to be fairly correct.

In addition we have considered the real option of constructing a small hydropower plant as a perpetual option; this is not entirely true; for instance, if an investor gets the license to construct a small hydropower plant in Norway this license is valid for five years, and he has the possibility to apply for a five year extension. After these ten years he must apply for a new license, which he may or may not get. If someone else has the possibility to apply for the same license he may lose the real option. Normally there is no one else who can apply for the 
same license because of ownership of the waterfall, so in our opinion this simplification is not an important source of error.

Dealing with uncertainty in inflow we have implicitly said that the average inflow from a great number of years is certain. The reason is that we have used long series of inflow, from 37 to 74 years of historical data from the actual or adjusted data from a similar waterway. In our opinion this is valid if there are not any significant climate changes during the lifespan of the plant.

Since small hydropower is considered to be environmentally friendly, it is eligible for receiving subsidies in many countries. In Europe, the most common instrument for promotion of new renewable capacity is feed-in tariffs. Eligible producers receive a fixed price adder for their output. Another arrangement is to invite tenders for a certain amount of renewable power, and select projects to receive subsidies. Third, a market arrangement for electricity certificates can be instituted, whereby electricity retailers need to buy certificates for a certain percentage of the electricity they sell. Eligible producers can sell certificates, and the government decides which production is eligible and what percentage the retailers should comply with. In Norway, small hydropower has not received any subsidies, and for this reason such subsidies have not been included in the model. The current governmental plan is to give future hydro projects below $3 \mathrm{MW}$ capacity a feed-in tariff of around $5 € / \mathrm{MWh}$.

\section{CONCLUSIONS}

We have presented a real options approach for making the optimal investment decision in small hydropower plants. We have shown that the investment decision can be divided into two steps. First the investor must find the value of the project if constructed and the investment cost. These two functions are combined to find a function for optimal size of the plant as a function of the long-term risk-free price of electricity. The next part is assessing the real option of being able to invest in the project. The real option takes into account the possibility to postpone the investment decision to get more information about the project profitability. We find the unique trigger for investing in the project. If the electricity price is below this price it is never optimal to invest in the project. If the price is above this unique trigger it is optimal to invest, using the function for the optimal size to determine the capacity of the plant.

We have assessed three projects using this method. Two of them are very good and should be initiated right away according to the real options method. The third project however should not. For this third project the power of the real options approach is more apparent, as the net present value is positive even though it is not optimal to invest. The reason is that if the investor were to invest at the current price, it would mean losing the value of the real option which at this price is higher than the net present value of the project.

Taking price- and inflow seasonality into account leads to lower optimal capacity and higher price trigger level. 


\section{REFERENCES}

T. Dangl, Investment and capacity choice under uncertain demand, European Journal of Operational Research 117 (3)(1999), 415-428

J.-P. Décamps, T. Mariotti, S. Villeneuve. Irreversible investment in alternative projects, Economic Theory 28 (2006), 425-448.

M.A.G. Dias, K.M.C. Rocha, J.P. Teixeira, The optimal investment scale and timing: a real option approach to oilfield development. Pravap-14 Working Paper, Petrobras-PUC-Rio. November 2003.

A.K. Dixit, R.S. Pindyck, Investment under uncertainty, Princeton University Press, 1994

S-E. Fleten, K.M. Maribu, I. Wangensteen, Optimal investment strategies in renewable distributed generation under price uncertainty, In press, Energy, 2005

S. Koekebakker, F. Ollmar, Forward curve dynamics in the Nordic electricity market, Managerial Finance 31 (6)(2005), 74-95.

J. Lucia, E.S. Schwartz, Electricity prices and power derivates - evidence from the Nordic power exchange, Review of Derivatives Research 5 (2002), 5-50.

R. McDonald, D. Siegel, The value of waiting to invest, The Quarterly Journal of Economics, 101 (4)(1986), 707-728.

NVE, Estimation of Potential for Small Hydropower in Norway - Assumptions, Methodology and Results, T. Jensen (ed), Norwegian Water Resources and Energy Directorate (NVE), Rep. 19,2004

Pilipovic, D. Energy Risk: Valuing and Managing Energy Derivatives, McGraw-Hill, 1997

R.S. Pindyck The dynamics of commodity spot and futures markets: A primer, Energy Journal $22(3)(2001) 1-29$

E.S. Schwartz, Valuing Long-Term Commodity Assets, Financial Management, 27 (1)(1998), $57-66$

E.S. Schwartz, J.E Smith, Short-Term Variations and Long-Term Dynamics in Commodity Prices, Management Science, 46 (7)(2000), 893-911.

ESHA, State of the Art of Small Hydropower Situation in EU-25, European Small Hydropower Association (www.esha.be), 2005 